\title{
A POLÍTICA CURRICULAR NO CONTEXTO DA INCLUSÃO E SEUS MECANISMOS DE DIFERENCIAÇÃO CURRICULAR
}

Amélia Maria Araújo Mesquita ${ }^{(*)}$ José Rafael Barbosa Rodrigues ${ }^{(*)}$ Kelly Paixão de Castro ${ }^{(* *)}$

\section{INTRODUÇÃO}

No Brasil, o século XXI se iniciou marcado pelo desenvolvimento de um conjunto de políticas, em especial curriculares, com a finalidade de garantir à educação escolar a todos os sujeitos por meio de uma orientação inclusiva. Desde a Lei de Diretrizes e Bases da Educação Nacional de 1996, (LDB, Lei 9.394/96), acena-se a essa perspectiva que se desdobra num conjunto de documentos que visam criar mecanismos em nível político para garantir à diversidade, propostas articuladas as suas singularidades de acesso ao bem comum, a educação básica.

Especificamente no que se refere à garantia de educação e escolarização de alunos com deficiência, por exemplo, a primeira orientação curricular, ainda na década de 1990, se deu por meio da proposta de adaptações curriculares. Contudo, Mesquita (2010) destacava que a proposta de adaptação mantinha intocado o currículo da escola, nesse sentido, compactuava com a perspectiva de Roldão (2003) e Pacheco (2008) ao afirmarem a pertinência da reconfiguração da ideia de diferenciação curricular. Nessa perspectiva, a diferenciação pode se constituir como um princípio filosófico orientador das práticas. (PLETSCH, SOUZA, ORLEANS, 2017).

O debate em torno da ideia de adaptar, flexibilizar, diferenciar ganhou destaque no contexto da inclusão (PLETSCH, 2009; REDIG, 2011; SILVA, 2012, 2016; CORRÊA, 2016) e no próprio desdobramento da política curricular, de tal modo que em um dos cadernos oriundos da Política Nacional da Educação Especial na perspectiva da Educação Inclusiva, assevera-se a necessidade de superação da ideia de adaptação pela perspectiva da diferenciação.

\footnotetext{
${ }^{(*)}$ Professora do Programa de Pós-graduação em Currículo e Gestão da Escola Básica (PPEB) do Núcleo de Estudos Transdisciplinares em Educação Básica (NEB)/UFPA. Vice-líder do Grupo de Estudos e Pesquisas em Currículo e Formação de Professores na perspectiva da Inclusão (INCLUDERE) e integrante do Grupo de Estudos e Pesquisas em Infâncias e Educação (INFANCE).

${ }^{(* *)}$ Mestre em Currículo e Gestão da Escola Básica (PPEB/NEB/UFPA). Integrante do Grupo de Estudos e Pesquisas em Currículo e Formação de Professores na perspectiva da Inclusão (INCLUDERE).

${ }^{(* * *)}$ Graduanda em Pedagogia (FACED/ICED/UFPA), bolsista de iniciação científica. Integrante do Grupo de Estudos e Pesquisas em Currículo e Formação de Professores na perspectiva da Inclusão (INCLUDERE).
} 
Ao contrário do que se pensa e se faz, as práticas escolares inclusivas não implicam um ensino adaptado para alguns alunos, mas sim um ensino diferente para todos, em que os alunos tenham condições de aprender, segundo suas próprias capacidades, sem discriminações e adaptações. (ROPOLI et al., 2010, p. 15, grifos no original).

Além dessa orientação, os documentos orientadores da organização do currículo da educação básica, com destaque às Diretrizes Curriculares Nacionais para a Educação Básica (DCNEB) (BRASIL, 2010), definem o currículo "como experiências escolares que se desdobram em torno do conhecimento, permeadas pelas relações sociais, articulando vivências e saberes dos estudantes com os conhecimentos historicamente acumulados e contribuindo para construir as identidades dos educandos" (BRASIL, 2010). Associada é essa compreensão, as DCNEB também orientavam quanto:

A organização do percurso formativo, aberto e contextualizado, deve ser construída em função das peculiaridades do meio e das características, interesses e necessidades dos estudantes, incluindo não só os componentes curriculares centrais obrigatórios, previstos na legislação e nas normas educacionais, mas outros, também, de modo flexível e variável, conforme cada projeto escolar [...] (BRASIL, 2010).

Essas orientações, assentadas numa concepção de currículo aberta às possibilidades de valorização do cotidiano e sua articulação com a garantia de acesso ao conhecimento historicamente produzido a partir de diferentes âmbitos de referência, ganha contorno singulares quando associada também à organização do percurso formativo marcada pela possibilidade de flexibilização/ diferenciação curricular como uma "estratégia" de inclusão.

Isso cria espaço para o desdobramento de diretrizes outras (educação especial, educação do campo, educação quilombola, entre outras), específicas às singularidades e diferenças que conformam a sociedade brasileira.

Contudo, a política curricular instaurada na segunda metade dos anos de 2010, inaugura uma outra perspectiva para o currículo da educação básica. Instituída em dezembro de 2017, a Base Nacional Comum Curricular (BNCC) configura-se documento de caráter normativo, aprovada em sua terceira versão para apenas duas etapas da Educação: a educação infantil e o ensino fundamental ${ }^{1}$. Já em 2018 o desdobramento da BNCC é produzido no Programa Mais Alfabetização (PMALF).

\footnotetext{
${ }^{1}$ A BNCC do Ensino Médio está em processo de aprovação.
} 
Diante desse cenário, neste artigo objetivamos problematizar a política curricular instituída a partir da aprovação da BNCC e seu desdobramento no PMALF, inferindo possíveis consequências da política na produção das práticas no contexto da educação inclusiva.

Vale destacar que, quando nos referimos à educação inclusiva, alargamos o entendimento de que ela pode trazer contribuições para os processos de escolarização de todos os sujeitos, sejam ou não o público-alvo da educação especial, e que, por ser um paradigma político, cultural e pedagógico, se desdobra em um conjunto de práticas que reverbera nos processos de ensinoaprendizagem na escola básica. Deste modo, ao problematizarmos a condução destas políticas curriculares, e dos processos de diferenciação/flexibilização, estamos nos referindo ao acesso de todos e todas ao conhecimento historicamente acumulado e organizado em forma de conteúdos de escolarização. Em suma, a problemática em tela, aprofunda os estudos que buscam analisar os embates e disputas que têm nas decisões curriculares, em nível de política e prescrição, produzido formas desiguais de distribuição do conhecimento, bem como, das tácitas formas de hierarquização e hegemonização do currículo escolar.

Para tanto, numa abordagem qualitativa, realizamos a análise documental tendo como fontes os textos curriculares da BNCC e do PMALF (Resolução, Manual de implementação do Programa e modelos de avaliação). Nesses documentos, centramos nossas análises nas prescrições e orientações para os anos iniciais do ensino fundamental, especialmente para o primeiro e segundo ano dessa etapa, que são objeto do Programa em questão. Buscamos depreender dos objetivos, dos objetos de conhecimento, das habilidades e competências presentes nos documentos, o que se configura “aprendizagem essencial” para a formação do sujeito.

A partir dos achados, identificamos elementos que afrontam os fundamentos da educação inclusiva - a valorização e respeito à diferença - por meio de mecanismos de diferenciação curricular negativa que constrangem as instituições escolares. Apontamos para a necessidade de se estreitar nas disputas, lutas e negociações pelo currículo escolar, tanto em nível de pesquisas acadêmicas, quanto da própria prescrição dos documentos, uma narrativa que supere a diferenciação negativa que, ao simplificar os conteúdos de escolarização, acaba por negar o acesso ao conhecimento elaborado e sistematizado, do qual todos e todas têm direito. Do mesmo modo, uma narrativa que centralize a democratização do conhecimento como elemento incontornável da função da escola pública, e que de fato se faça inclusiva. 


\section{CURRÍCULO, CONHECIMENTO E CONTEÚDO: CAMPOS EM DISPUTA}

As reflexões e tensões sobre quais conhecimentos devem ser ensinados na escola básica tornam cada vez mais relevantes os estudos que se proponham a tematizar os processos de seleção, organização e distribuição dos conteúdos de escolarização. No cerne da definição e discussão de políticas e práticas educacionais no contexto da inclusão, este questionamento ganha fôlego e importância na medida em que podem ser associados ao cunho político que o currículo assume para a democratização da sociedade. Ao mesmo tempo, este debate se configura como importante, se assumirmos que a seleção de determinados conteúdos estão indiscutivelmente associados aos processos de subjetivação, qual seja, a formação de identidades e sujeitos específicos.

Buscar identificar e problematizar quais conteúdos estão sendo dirigidos para as práticas de escolarização no atual momento político, social, cultural e econômico, e sua direta relação com a democratização da escola pública, lateja no sentido da materialização de condições concretas para uma educação que se quer efetivamente inclusiva, de qualidade e para formação de sujeitos críticos.

No contexto brasileiro, o movimento político que tem dado sustentação à educação inclusiva nas últimas décadas, e nos últimos anos de forma mais contundente, só pode ser analisado dentro do contexto daquilo que chamamos de educação básica. Conforme Cury (2002), foi somente com a Constituição Federal de 1988 que se teve possibilidade - mais tarde na LDB de 1996 - que a educação básica, enquanto um conceito importante, emergisse no sentido daquilo que o art. 21 define como um nível da educação nacional que engloba a educação infantil, o ensino fundamental e o ensino médio. Os objetivos da educação básica são determinados pelo art. 22, que assevera que esta "[...] tem por finalidade desenvolver o educando, assegurar lhe a formação comum indispensável para o exercício da cidadania e fornecer-lhe meios para progredir no trabalho e em estudos posteriores" (BRASIL, 1996).

Na leitura feita por Cury (2002), a educação básica e, portanto, a escolarização, é um patrimônio cultural no qual todos/as têm o direito ao acesso, em meio as suas especificidades e diferenças individuais. Deste modo, o conceito de educação básica que advém da LDB de 1996, aciona dispositivos para problematizarmos um elemento que sem dúvidas está associado aos desafios para a escolarização dos sujeitos e suas diferenças e para a garantia do acesso a este patrimônio cultural: o currículo escolar.

Ainda que existam variadas formas de significar o que vem a ser currículo, o que Lopes (2006, p. 35) define como “[...] discursos que são base da produção de sentidos e significados para as políticas de currículo em múltiplos contextos, em uma constante tensão homogeneidade- 
heterogeneidade", e ainda que estes sentidos e significados estejam em incessantes negociações para dar sentido ao campo, é possível visualizar que, a despeito das variadas abordagens epistemológicas que tem dado sustentação ao discurso curricular contemporâneo, o currículo enquanto conhecimento escolar selecionado, parece se sobrepor como uma discussão incontornável no estudos curriculares; ainda que se necessite aprofundar os debates em relação aos fatores políticos, sociais, econômicos e culturais que tem dado legitimação à política de conhecimento oficial (APPLE, 2011).

De acordo com Sacristán (1998, p. 125) “o termo currículo provem da palavra latina currere, que se refere à carreira, a um percurso que deve ser realizado e, por derivação, a sua representação ou apresentação". Guardando uma amplitude conceitual, que se estabelece a partir do contato com a realidade, fazendo alusão ao conteúdo de planos e projetos de natureza educativa ou ainda à finalidade educativa com que estes projetos educativos são produzidos (SACRISTÁN, 1998). Diante de sua condição de produto humano, constituído por intencionalidades diversas, este percurso é marcado por elementos históricos e culturais no processo de escolarização de diferentes tempos e sociedades, sendo expresso por Sacristán (1988, p. 34) como "O projeto seletivo de cultura, cultural, social, política e administrativamente condicionado, que preenche a atividade escolar e que se torna realidade dentro das condições da escola tal como se acha configurada".

Young (2014, p.192), argumenta que responder a pergunta "o que todos os alunos deveriam saber ao deixar a escola?", materializa o fato de que não existe, para o autor, problema mais importante para ser debatido, do que o curricular. Se a educação ocupa-se em capacitar as pessoas para adquirirem um determinado conhecimento que a levem para além do imediatismo cotidiano e que provavelmente não teriam acesso em outros espaços se não na escola, é tarefa da teoria do currículo a análise deste conhecimento. Nesse sentido, afirma:

Os currículos são a forma desse conhecimento educacional especializado e costumam definir o tipo de educação recebida pelas pessoas. Precisamos entender os currículos como formas de conhecimento especializado para podermos desenvolver currículos melhores e ampliar as oportunidades de aprendizado. É esse tipo de meta que dá sentido à teoria do currículo, assim como tratamentos e remédios melhores dão sentido à ciência médica (YOUNG, 2014, p.197).

Com isto, o autor centraliza a discussão do conhecimento que tem constituído os currículos escolares, como tema das decisões políticas que se tem tomado em relação à escola básica, e suas formas de organização. Destaca, do mesmo modo, o papel da teoria do currículo para com este problema. 
Assumimos, deste modo, a definição do que é conhecimento escolar a partir das posições de Young (2007, 2010), ao demarcar que a função desta instituição perpassa pela tarefa de transmitir um conhecimento que é próprio da escola, que se diferencia do conhecimento cotidiano. Assim, trata-se de um conhecimento poderoso, pois este refere-se "ao que o conhecimento pode fazer, como, por exemplo, fornecer explicações confiáveis ou novas formas de pensar a respeito do mundo" (YOUNG, 2007, p. 1294).

Deste modo, consideramos que oportunizar o acesso a uma educação de qualidade e que priorize um currículo centrado nos conhecimentos socialmente relevantes para o nosso momento histórico, está alinhado à defesa de uma escola que de fato se quer inclusiva.

Feitas estas considerações, é preciso demarcar que, para os efeitos desta investigação, compreendemos o currículo escolar como um elemento construído a partir da influência do ambiente e das relações de ensino-aprendizagem entre os sujeitos. Assim, o currículo e sua apresentação é resultado das práticas de confecção e acabam por mediar a relações entre conteúdo e cultura. Demandando que influências do contexto externo sejam avaliadas, como por exemplo, "o exercício de práticas políticas, econômicas e sociais" (SACRISTÁN,1998, p. 129).

Se por um lado, criar mecanismos de acesso ao conhecimento elaborado e sistematizado é um direito de todos e todas, para o qual a função social da escola se destina, este processo só pode ser entendido em sua inteireza, se associado ao reconhecimento da diferença como elemento constituinte dos processos de ensino-aprendizagem. Em outras palavras, em uma perspectiva inclusiva, a garantia das aprendizagens de determinados conteúdos de escolarização, no qual todos e todas têm o direito ao acesso, por uma questão de igualdade e justiça social, não pode ser visto como uma tarefa alheia aos modos muito específicos e subjetivos do desenvolvimento humano.

\section{A POLÍTICA CURRICULAR PARA OS ANOS INICIAIS DO ENSINO FUNDAMENTAL}

Para compreender como se configura a constituição de uma política curricular é importante primeiramente defini-la a fim de se tornarem explícitas as intenções que lhes estão ocultas. De acordo com Sacristàn (2000, p. 109) a política curricular é:

Um aspecto específico da política educativa, que estabelece a forma de selecionar, ordenar e mudar o currículo dentro do sistema educativo, tornando claro o poder e a autonomia que diferentes agentes têm sobre ele, intervindo dessa forma, na distribuição do conhecimento dentro do sistema escolar e incidindo na prática educativa, enquanto apresenta o currículo a seus consumidores, ordena seus conteúdos e códigos de diferente tipo. 
Nessa perspectiva, desde os anos 1990, com a LDB de 1996, um conjunto de documentos de caráter prescritivo e orientador, tem produzido uma narrativa em relação aos conteúdos que devem ser ensinados na escola básica.

Em especial, para os anos iniciais do ensino fundamental, com a ampliação do ensino fundamental de nove anos (que inicia aos seis de idade) o chamado "ciclo de alfabetização" ganha destaque em relação aos seus elementos tanto pedagógicos quanto curriculares, de modo que, ainda que se possam fazer críticas a estes documentos, suas formas de organização (por competências, direitos de aprendizagem, ou mesmo objetivos de aprendizagem), e aos próprios conteúdos em suas dinâmicas de seleção, têm formado um corpus prescritivo que é amparado pela própria legislação brasileira, como LDB, em seu Art. 26, que determina:

Os currículos de educação infantil, do ensino fundamental e do ensino médio devem ter base nacional comum, a ser complementada, em cada sistema de ensino e em cada estabelecimento escolar, por uma parte diversificada, exigidas pelas características regionais e locais da sociedade, da cultura, da economia e dos educandos (BRASIL, 1996, grifo nosso).

Os destaques ao excerto realçam a ideia de educação comum, sem necessariamente ser homogênea, haja vista o resguardo tanto aos aspectos sociais culturais, quanto individuais do sujeito.

Contudo, na segunda década do século XXI, indiscutivelmente, observamos uma política de alfabetização se desenhando neste contexto de definição de conteúdos de escolarização para os anos iniciais. Uma série de programas e projetos se desenrolam como uma política que vem sendo adotada pelos sistemas escolares dos estados e municípios brasileiros, de modo a efetivar a constituição dos currículos escolares.

No contexto histórico que se movimenta para a efetivação de uma educação inclusiva, observar estas políticas e programas, torna-se uma tarefa incontornável para a atual política de inclusão. Afinal, estes documentos orientadores se consolidam como uma prescrição: "Se as opções de política curricular a intervenção da administração sobre os conteúdos de escolaridade são reguladoras da prática, podemos dizer que a planejam" (SACRISTAN, 1998, p. 233).

Em 2012 surge uma política importante para a definição de conteúdos a serem trabalhados na educação básica, nos três primeiros anos do ensino fundamental especificamente: o Pacto 
Nacional pela Alfabetização na Idade Certa (PNAIC) ${ }^{2}$. Com foco na alfabetização na perspectiva do letramento, o Pacto se propõe a ser uma ação articulada com vistas à alfabetização de todas as crianças brasileiras até os oito anos de idade. Tendo em vista um quadro histórico de direitos negados, como o direito de escolarização, o Pacto se define como uma "[...] luta para garantir o direito de alfabetização plena a meninos e meninas, até o final do ciclo de alfabetização" (BRASIL, 2012, p. 10).

Embora trate-se de uma política de formação continuada, o PNAIC tem assumido um caráter curricular (ver figura 1) se considerarmos que seus documentos estão marcados por processos de prescrição e organização do conhecimento escolar destinado aos sistemas escolares estaduais e municipais, uma vez que estes acabam alinhando seus currículos ao Pacto.

Figura 1. Organização curricular do PNAIC.

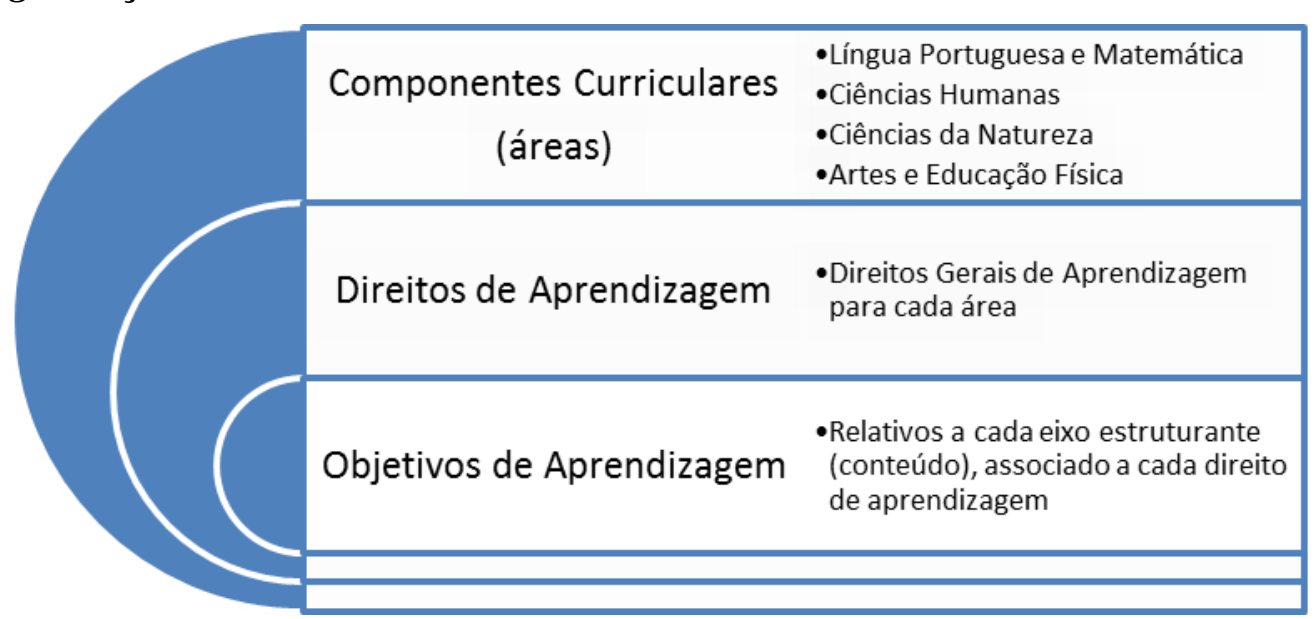

Fonte: Elaborado pelos autores com base no caderno "Direitos de Aprendizagem" do PNAIC.

Embora existam críticas ao modo de organização por 'direitos de aprendizagem' e 'objetivos de aprendizagem', e nas suas implicações pedagógicas, inclusive no que se refere aos cadernos que discutem a perspectiva inclusiva (CASTILHO; BEZERRA, 2016), vale ressaltar que o PNAIC ao assumir uma visão mais ampliada de alfabetização deflagra uma abordagem alternativa na sistematização dos conhecimentos escolares. Ao priorizar não apenas a Língua Portuguesa e Matemática, mas também outros campos de conhecimento, o Pacto abre a possibilidade para uma visão mais alargada de escolarização e da sua importância para a formação humana.

A meta de alfabetizar meninas e meninos até 8 anos de idade não se cumpre na esfera exclusiva da linguagem escrita, mas sim de forma contextualizada, ampla e plural, envolvendo todo o mundo físico e biopsicossocial das crianças. A possibilidade de apropriar-se de conhecimentos acerca do mundo físico e social, das práticas de

\footnotetext{
${ }^{2}$ Vale destacar que em 2017, por meio da Portaria 826/2017, o PNAIC é reconfigurado e ampliado para a educação infantil.
} 
linguagem, de capacidades para interagir, de modo autônomo, por meio de textos orais e escritos, de experimentar situações diversificadas de interlocução na sociedade será oferecida pela escola nas tantas experiências criativas, imaginativas e sensoriais ofertadas às crianças, desde pequeninas (BRASIL, 2012, p. 19).

Concomitante ao PNAIC iniciam-se os debates em torno da definição de uma BNCC. Aprovada em dezembro de 2017, a BNCC é um documento de caráter mandatório e para sua implantação, ficou definido um prazo de dois anos, a contar da sua aprovação, para adequação das redes à nova perspectiva curricular.

A BNCC se estrutura em torno de dez competências gerais, as quais orientarão a organização pedagógico-curricular das escolas públicas e privadas. As competências são definidas pela Base como "a mobilização de conhecimentos [...], habilidades [...], atitudes e valores para resolver demandas complexas da vida cotidiana, do pleno exercício da cidadania e do mundo do trabalho" (BRASIL, 2017). A partir delas são estruturados e definidos todos os demais elementos, conforme ilustra a imagem a seguir:

Figura 2. Estrutura curricular da BNCC para o ensino fundamental.

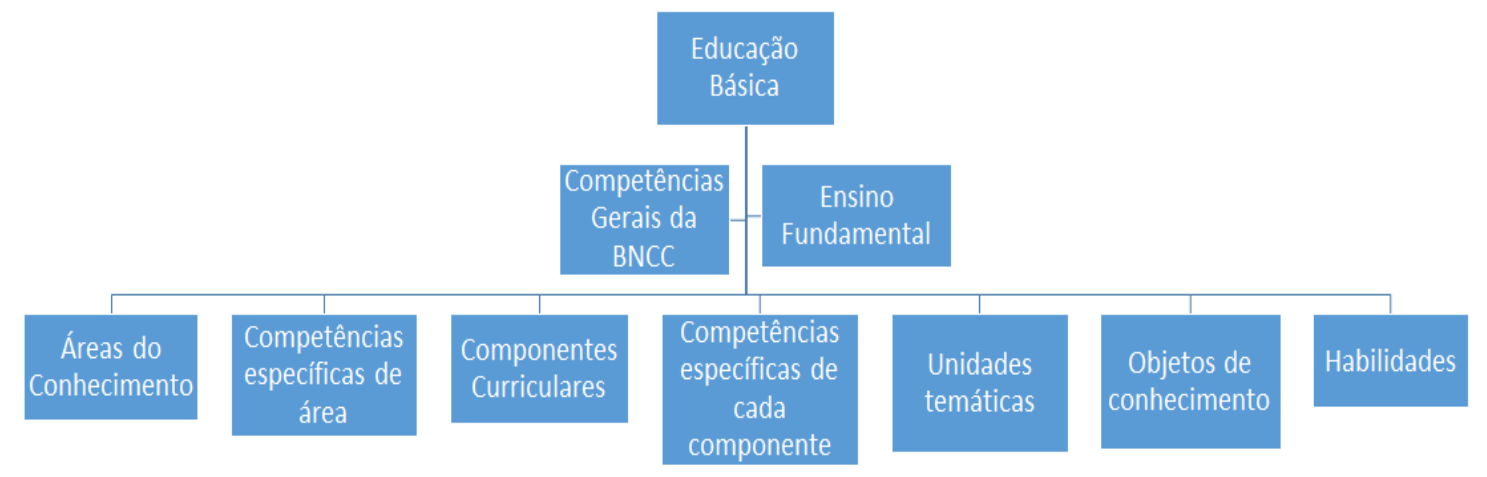

Fonte: Elaborado pelos autores com base no documento da BNCC, 2017.

Observando a ilustração acima, as competências são o "tom” da BNCC e a partir delas são estruturados: os componentes curriculares, as unidades temáticas, os objetos de conhecimento e as habilidades. As áreas de conhecimento são os grandes campos onde se articulam diferentes componentes curriculares. Estes são as disciplinas que comporão obrigatoriamente o currículo escolar. Para cada disciplina são definidas as unidades temáticas e a partir delas, começamos a visualizar os conhecimentos selecionados dentro de cada disciplina. O maior detalhamento desses conhecimentos - portanto, os conteúdos específicos selecionados - está nas habilidades. Esta última é assumida como práticas cognitivas e socioemocionais. 
Para os anos iniciais são definidas como áreas do conhecimento e seus respectivos componentes curriculares: Linguagens (Língua Portuguesa, Arte e Educação Física); Matemática (Matemática); Ciências da Natureza (Ciências); Ciências Humanas (História e Geografia); Ensino Religioso (Ensino Religioso). Cabe ressaltar que destas ganham destaque a área de Linguagem e Matemática, especificamente nos componentes curriculares Língua Portuguesa e Matemática. Esse destaque fica evidente na quantidade de habilidades que se associam aos objetos de conhecimento. Para os anos iniciais estão previstos o desenvolvimento de pelo menos 568 habilidades entre os diferentes componentes curriculares, com maior destaque para Português e Matemática (209 e 119, respectivamente) e de forma discreta aparecem as habilidade para o Ensino Religioso e Arte (36 e 29 , respectivamente).

Esse panorama revela de imediato o status que possuem as disciplinas de Português e Matemática, centralidade essa que não é recente nos currículos.

É interessante destacar que logo após a aprovação da BNCC (dezembro de 2017), foi instituído em fevereiro de 2018, por meio da Portaria Ministerial 142/2018, o PMALFA, cujo objetivo é "fortalecer e apoiar as unidades escolares no processo de alfabetização - para fins de leitura, escrita e matemática - dos estudantes no $1^{\circ}$ ano e no $2^{\circ}$ ano do ensino fundamental" (BRASIL, 2018a).

O Programa é pensado como uma estratégia do governo federal diante dos baixos índices de desempenho dos estudantes na Avaliação Nacional de Alfabetização (ANA). Para tanto, se propõe a investir na contratação do assistente de alfabetização que, de acordo com o manual operacional do Programa, garantirá apoio adicional de $5 \mathrm{~h}$ e $10 \mathrm{~h}$ semanais para instituições escolares não vulneráveis e vulneráveis ${ }^{3}$, respectivamente.

Estão entre as finalidades do Programa:

[...] III. integrar as atividades ao Projeto Político Pedagógico - PPP da rede e das unidades escolares; IV. viabilizar atendimento diferenciado às unidades escolares vulneráveis; [...] VI. assegurar o monitoramento e a avaliação periódica da execução e dos resultados do Programa; [...]; [...] X. avaliar o impacto do Programa na aprendizagem dos estudantes, com o objetivo de gerar evidências para seu aperfeiçoamento; [...]. (BRASIL, 2018a)

\footnotetext{
${ }^{3}$ São consideradas instituições escolares vulneráveis aquelas "em que mais de $50 \%$ dos estudantes participantes do SAEB/ANA tenham obtido resultados em níveis insuficientes nas três áreas da referida avaliação (leitura, escrita e matemática); e que apresentarem Índice de Nível Socioeconômico muito baixo, baixo, médio baixo e médio, segundo a classificação do Instituto Nacional de Estudos e Pesquisas Educacionais Anísio Teixeira - INEP” (BRASIL, 2018a).
} 
Pelo exposto, ainda que o processo de implantação da BNCC tivesse um prazo de dois anos para se instituir nos espaços escolares, já em início de 2018 é aprovado um programa de indução à atual perspectiva curricular, que, não obstante, além de fortalecer a política, minimiza o espaço de debate e discussão para a produção de propostas curriculares.

Observa-se, portanto, a produção de estratégias (CERTEAU, 1998), que imprimem uma lógica para o cotidiano escolar com pouca autonomia, considerando que a atual política curricular para os anos iniciais define: as competências, os conteúdos de ensino (fortemente presente nas habilidades de cada objeto de conhecimento), e os mecanismos de controle (por meio de testes padronizados).

Neste cenário, e considerando que o foco dos anos iniciais é o processo de alfabetização, vale destacar aquilo que o Programa define como "estar alfabetizado":

Para ser considerado alfabetizado em Língua Portuguesa, o estudante deve compreender o funcionamento do sistema alfabético de escrita; construir autonomia de leitura e apropriar-se de estratégias de compreensão e de produção de textos. Da mesma forma, para ser considerado alfabetizado em matemática, ele deve aprender a raciocinar, a representar, a comunicar, a argumentar, a resolver problemas em diferentes contextos, utilizando conceitos, procedimentos e fatos matematicamente. (BRASIL, 2018, p. 3, grifo nosso).

Os destaques acima demarcam as competências básicas que as crianças devem possuir para serem consideradas alfabetizadas, com fortes marcas na eficiência de mecanismos técnicos ou procedimentais. Evidencia-se também que a ideia de alfabetização passa a ser reduzida a dois campos, diferente do que vinha sendo orientação no PNAIC que definia a alfabetização em diferentes campos curriculares e numa vinculação direta com o letramento.

O atual contorno das políticas de currículo, com foco nos anos iniciais, especialmente nos dois primeiros anos que agora conformam o "ciclo" de alfabetização, está marcado, por pelo menos dois elementos que merecem destaque: 1) As estratégias de implantação e controle forjam um tipo ideal de escola e aluno, constituindo-se, portanto, em mecanismos de homogeneização; 2) O Programa Mais Alfabetização, ao categorizar as instituições em vulneráveis e não vulneráveis cria constrangimentos por meio de mecanismos de diferenciação curricular negativa. 


\section{DIFERENCIAÇÃO CURRICULAR: TENSÕES ENTRE A ATUAL POLÍTICA CURRICULAR E A PERSPECTIVA INCLUSIVA}

A diferenciação curricular não é um conceito e nem uma proposta recentes. Na história da educação a diferenciação se apresenta em duas grandes perspectivas: uma negativa, quando cria mecanismos de segregação, e outra positiva, quando reconhece a necessidade de investir na produção de caminhos distintos para acesso a um direito comum. De acordo com Roldão (2003), a diferenciação curricular pode se dar em três níveis: o político (na organização dos sistemas e das escolas); o organizacional (referente aos patamares de exigência dentro de um mesmo currículo escolar); e o pedagógico-curricular (nos modos de organizar o ensinar e o aprender face às aprendizagens comuns)

Em particular, no contexto da educação inclusiva, a diferenciação curricular é assumida como possibilidade de materialização de práticas que assegurem a todos e todas, por vias diversificadas, acesso a escolarização qualificada e ao conhecimento poderoso.

Pletch, Souza e Orleans (2017) destacam a necessidade da diferenciação curricular e do desenho universal da aprendizagem se constituírem princípios para a inclusão escolar de forma a garantir uma estrutura pedagógica e curricular que atenda a diversidade. Contudo, cabe questionar: no atual contexto das políticas curriculares, de que forma viabilizar tal perspectiva num cenário de engessamento do currículo?

Para Sacristán (2000, p. 107)

A política sobre o currículo é um condicionamento da realidade prática da educação que deve ser incorporado ao discurso sobre o currículo; é um campo ordenador decisivo, com repercussões muito diretas sobre essa prática e sobre o papel e margem de atuação que os professores e os alunos têm da mesma.

Diante dessa assertiva, a assunção da normativa posta pela BNCC produz um reducionismo do currículo, que se assevera nos programas que atingem de forma direta o cotidiano escolar.

Segundo o próprio documento, a BNCC se propõe a definir "um conjunto orgânico e progressivo de aprendizagens essenciais que o aluno deve desenvolver” (BRASIL, 2017, p. 7, grifo nosso). Para os anos iniciais, especialmente o primeiro e segundo ano das escolas públicas, são aprendizagens essenciais leitura, escrita e matemática, conforme consta na BNCC e no seu desdobramento por meio do PMALFA.

A ideia de aluno e aprendizagem, na perspectiva da homogeneização que a BNCC produz, é monitorada por mecanismo de controle. No PMALFA, por exemplo, são apresentadas matrizes de 
referência de avaliação diagnóstica (ver figura 3), formativa e somativa que objetivam “acompanhar" a progressão do aluno. A esse respeito, é importante notar que as estratégias da atual política curricular "invadem" o cotidiano da escola que, além de serem submetidas a testes de avaliação em larga escala, agora também são submetidos ao uso de instrumentos de acompanhamento definidos externamente à instituição escolar.

Figura 3. Matriz de referência de avaliação diagnóstica-Português $1^{o}$ ano.
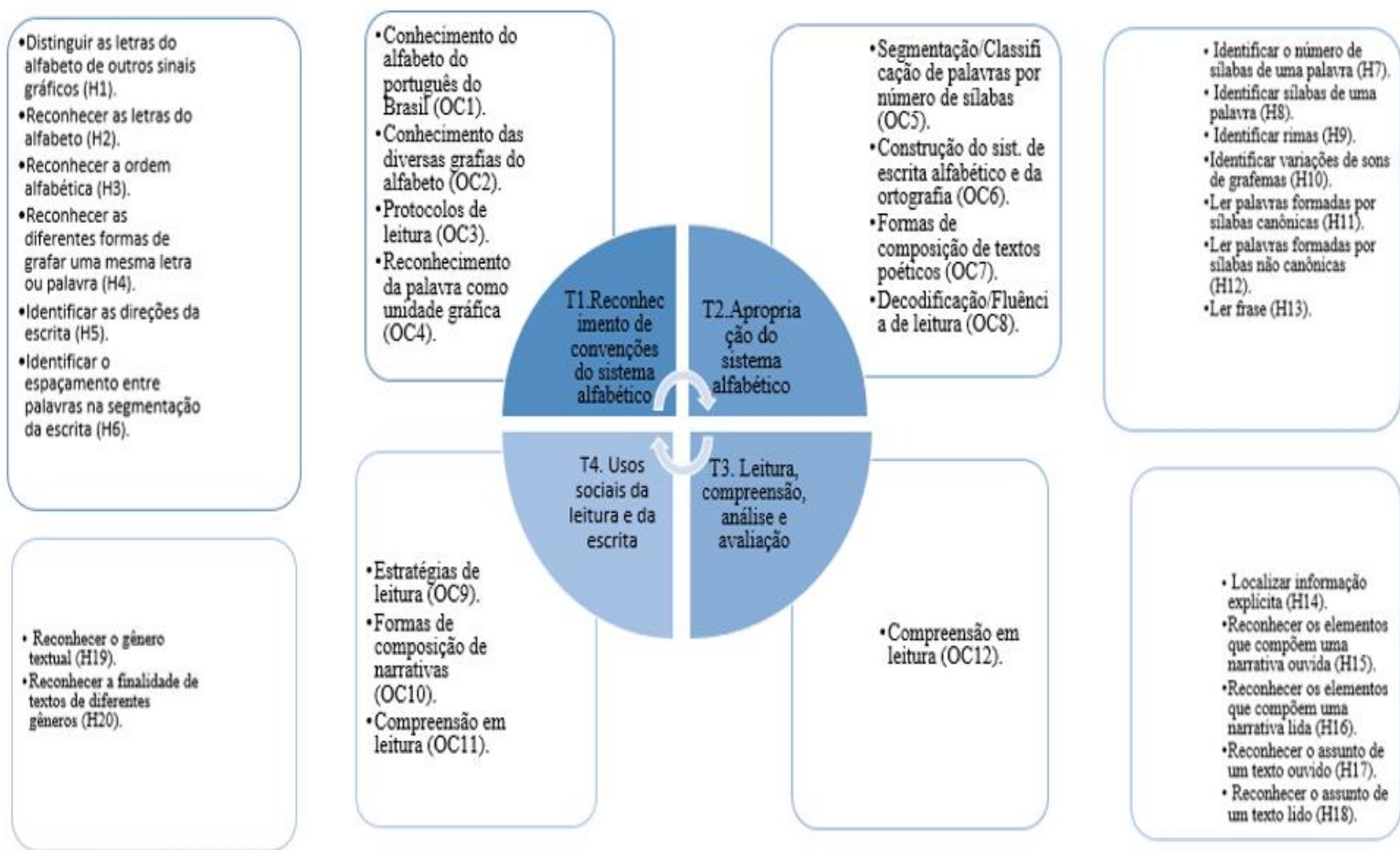

Fonte: Elaborado pelos autores com base nos Materiais de Apoio - PMALF, 2018b.

Conforme observamos na ilustração, para o diagnóstico das habilidades iniciais, a matriz centra em conteúdos de caráter abstrato e pouco significativo para crianças de seis anos. Reconhecer e distinguir letras, grafá-las de forma diferente evidenciam a seleção de conhecimentos, e também de métodos, pouco ocupados com a contextualização e o sentido da linguagem escrita. Temos assim, a seleção de conhecimentos procedimentais que, de fato, são fundamentais no processo de alfabetização, mas que isolados, e estruturados numa organização de progressão da parte para o todo, perdem a dimensão de conhecimento poderoso. Isto, porém, não significa que não reconhecemos o lugar da alfabetização para a escolarização e para a garantia do acesso ao conhecimento poderoso, no entanto, estes conhecimentos não podem ter fim em si mesmo, e servir como prerrogativa para aprendizagens mais complexas.

Para além disso, cabe destacar algumas estratégias do PMALF definidas nas competências dos entes federados e sujeitos do processo. De acordo com o manual do PMALF compete aos 
estados e municípios, entre outras coisas "garantir, no período definido pelo MEC, a aplicação das avaliações diagnósticas e formativas a todos os estudantes regularmente matriculados no $1^{\circ}$ ano e no $2^{\circ}$ ano do ensino fundamental e a inserção dos seus resultados no sistema do Programa" (BRASIL, 2018a, p. 8). Compete, entre outros, ao assistente de alfabetização a:

[...] elaboração e apresentação à coordenação de relatório dos conteúdos e de atividades realizadas mensalmente; $\neg$ pelo acesso ao Sistema de Orientação Pedagógica e Monitoramento do PMALFA/CAEd digital para o cadastro das atividades pedagógicas desenvolvidas, para que o Professor ou o Coordenador da escola analisem e validem posteriormente [...].

Ainda que consideremos que a prática não é mera tradução de políticas, as estratégias de controle estão fortemente presentes por meio de instrumentos que podem seduzir o fazer docente, com a falsa impressão de servirem de orientação e medida da "qualidade" da educação oferecida ao aluno. Como se configuram em instrumentos "padrão", esses vão verticalmente na contramão da valorização da diferença, portanto, do princípio inclusivo.

Assim, temos na composição conhecimento-avaliação os insumos fundamentais da atual política curricular para os primeiros anos do ensino fundamental. Tal composição desconsidera a diversidade sociocultural do Brasil e descaracteriza a ideia de "caminhos distintos para garantias comuns", na medida em que define padrões mínimos e instrumentos padrões como ideia de “qualidade da educação”, em especial da educação pública, alvo dos programas.

Tem-se, nessa conformação, a sonegação de acesso aos alunos em situações sociais menos favorecidas ao conhecimento poderoso. Sonegação esta que se dá pela redução do currículo a campos específicos. Redução também que se faz ao tipo de conteúdo que está sendo proposto.

Destaca-se a isso o fato da BNCC ter retirado da sua versão final discussões referentes às modalidades da educação. Isso implica na desconsideração das especificidades atinentes à educação do campo, à educação indígena, à educação especial, para citar alguns.

Soma-se a essas questões a classificação das instituições escolares em vulneráveis e não vulneráveis, demarcando essa "diferença" a dois fatores combinados: número significativo de alunos com notas baixas na avaliação da ANA/SAEB e condições de índice de nível socioeconômico. Tal diferenciação impõe uma marca à escola pública que "naturalmente" a distingue negativamente das instituições privadas: a marca da condição de vulnerabilidade, porque, mesmo que classificada como “não vulnerável”, é não vulnerável em relação às vulneráveis, o que não lhe garante padrão de qualidade. 
Vale destacar que tal classificação suprime a valorização das diferenças biopsicossociais e põe em evidência para a escola pública apenas a condição de vulnerabilidade.

Diante desses apontamentos, temos em vistas de implementação um projeto curricular que, desde os anos iniciais (quiçá na educação infantil), inverte a lógica de diferenciação curricular, recuperando seus pressupostos de hierarquização e, portanto, infringe o princípio da educação inclusiva.

Compreendemos, no entanto, que os processos de seleção e organização do conhecimento escolar tanto na BNCC, quanto no PMALF, e por consequência, as formas assumidas por estas políticas para as modificações e diferenciações - sejam negativas como apontamos, ou mesmo as positivas - estão diretamente relacionadas aos contextos políticos, culturais e econômicos que tem disputado o conhecimento a ser ensinado nas escolas. As formas como estas políticas têm assumido a seleção e organização do currículo, portanto, estão alinhadas ao tipo de sujeito que se quer formar, e a sociedade que se quer forjar.

Pacheco (2003, p. 29), amplia este debate afirmando que tanto a forma quanto o conteúdo das políticas de currículo, não são decidias por critérios meramente técnicos, e nem de argumentos teóricos e científicos, mas sim “[...] na base de opções políticas que, em termos ideológicos representam noções distintas de Estado e lógicas proporcionais às influencias dos grupos sociais com interesses e valores educativos".

Ora, as políticas de currículo contemporâneas inegavelmente resguardam as lutas, negociações e disputas que tem margeado a definição dos conteúdos escolares para a educação básica brasileira. O conhecimento escolar é alvo deste constante confronto político, ideológico e social para a definição do que conta como relevante para adentrar à escola. Como argumentam, Moreira e Silva (2011, p. 80):

O currículo está implicado em relações de poder, o currículo transmite visões sociais particulares e interessadas, o currículo produz identidades individuais e sociais particulares. O currículo não é um elemento transcendente e atemporal - ele tem uma história, vinculada as formas específicas e contingentes de organização da sociedade e da educação.

Diante disso, temos a tarefa da vigilância e resistência, buscando continuadamente a construção de mecanismos de diferenciação curricular que reconheçam e assumam a diferença e diversidade, potencializando a produção de práticas curriculares assentadas em perspectivas inclusivas. 


\section{CONSIDERAÇÕES FINAIS}

Prover uma sociedade democrática significa constituir formas específicas de democratizar o acesso aos bens culturais produzidos pela humanidade, como o conhecimento escolar. Em outras palavras, democratizar a escola pública implica em subsidiar a constituição de práticas que garantam a efetiva aprendizagem dos conhecimentos acumulados pela ciência, pela cultura e pelas artes, elaborados e sistematizados para as gerações que adentram na escola. Constituindo, assim, processos inclusivos e de equidade, que, reconhecendo as diferenças e a heterogeneidade da sociedade brasileira, possam formar estratégias de diferenciação/flexibilização pedagógicas e curriculares, para a garantia das aprendizagens do patrimônio cultural comum a todos e todas.

As políticas curriculares que tem desenhado os conteúdos de escolarização para os anos iniciais do ensino fundamental apresentam um corpus prescritivo que tem orientado o desenvolvimento curricular das escolas brasileiras. Os documentos, como foi observado na análise da BNCC e do PMALF, estão fortemente marcados por uma lógica que se assume os conteúdos de alfabetização como pré-requisito para a aprendizagem de conhecimentos de outros campos científicos, o que acaba por hierarquizar estes conhecimentos, assumindo uma lógica que parte sempre do simples para o complexo, e do concreto para o abstrato, quando a inteligência humana assume outras dinâmicas de construção muito mais complexas.

Para além da hierarquização e da homogeneização dos conteúdos priorizados nos documentos analisados, pode-se apontar, do mesmo modo que, ao criar mecanismos de hierarquização e homogeneização, classificando as escolas em vulneráveis e não vulneráveis, retoma a forma de diferenciação curricular que mais colabora para segregação e conformação de guetos por exclusão. Nesse sentido, a atual perspectiva curricular, no modo como vem se desenhando é um acinte à consolidação de uma escola se deseja inclusiva, portanto, nos coloca diante do desafio da vigilância e da resistência contra as formas de opressão via currículo escolar. 


\section{REFERÊNCIAS}

APPLE, M. A política do conhecimento oficial: faz sentido a ideia de um currículo nacional? In: MOREIRA, Antônio F.; SILVA, Tomaz T. Currículo, Cultura e Sociedade. 12 ed. São Paulo: Cortez, 2011.

BRASIL. Lei 9.394, de 20 de dezembro de 1996. Estabelece as diretrizes e bases da educação nacional. Diário Oficial da União. Brasília: Poder Legislativo, 23 dez. 1996, sec. I, n. 248, p. 27.833.

Política Nacional de Educação Especial na Perspectiva da Educação Inclusiva. MEC/SECADI, 2008. Disponível em: <http://portal.mec.gov.br/arquivos/pdf/politicaeducespecial.pdf>. Acesso em: 10 set. 2018.

Diretrizes Curriculares Nacionais da Educação Básica. MEC/SAEB/SEB/DICEI, 2010. Disponível em: <http://portal.mec.gov.br/docman/julho-2013-pdf/13677-diretrizes-educacao-basica-2013-pdf/file〉. Acesso em: 10 set. 2018.

Pacto Nacional pela Alfabetização na Idade Certa: formação do professor alfabetizador. Caderno de Apresentação. Ministério da Educação, Secretaria de Educação Básica, Diretoria de Apoio à Gestão Educacional. -Brasília: MEC, SEB, 2012. Disponível em: <http://pacto.mec.gov.br/materiais-listagem/item/download/21_9945a29 41359afb9a5bc726869f697c5>. Acesso em: 30 ago. 2018.

Base Nacional Comum Curricular (BNCC). MEC/CONSED/UNDIME. 2017. Disponível em: <http:// basenacionalcomum.mec.gov.br/wpcontent/uploads/2018/02/bncc-20dez-site.pdf>. Acesso em: 15 set. 2018.

Manual Operacional do Sistema de Orientação Pedagógica e Monitoramento. Brasília: MEC Mais Alfabetização, 2018a. Disponível em: <http://portal.mec.gov.br/docman/abril-2018-pdf/85691-manual-operacionalpmalfa-final/file>. Acesso em: 30 ago. 2018.

Matriz de Referência para Avaliação: material de apoio. Mais Alfabetização/MEC/CAEd/UFJF, $2018 b$. Disponível em: <https://maisalfabetizacao.caeddigital.net/\#!/material-apoio〉. Acesso em: 30 ago. 2018.

CASTILHO, T. B.; BEZERRA, G. F. Educação Especial e Inclusão Escolar Nos Cadernos do Pacto Nacional pela Alfabetização na Idade Certa. Revista Tempos e Espaços em Educação, v. 9, n. 19, p. 193-208, 2016. Disponível em: <https://seer.ufs.br/index.php/revtee/article/view/5605/4621>. Acesso em: 20 set. 2018.

CERTEAU, Michel de. A invenção do Cotidiano. 3. ed. Petrópolis: Editora Vozes, 1998.

CORREIA, G. B. Educação Especial e Currículo: das adaptações curriculares à acessibilidade curricular, 2016.

CURY, Carlos Roberto Jamil. A educação básica no brasil. Educação e Sociedade. Campinas, vol. 23, n. 80, p. 168200, set. 2002. Disponível em: <http://www.scielo.br/pdf/es/v23n80/12929.pdf>. Acesso em: 14 set. 2018.

MESQUITA, Amélia Maria Araújo. Currículo e educação inclusiva: as práticas curriculares nacionais. Espaço do Currículo, v. 3, n. 1, p. 305-325, mar./set. 2010. Disponível em: <http://www.periodicos.ufpb.br/index.php/rec/article/ viewFile/9093/4781>. Acesso em: 10 set. 2018.

MOREIRA, Antônio Flávio. SILVA, Tomaz Tadeu. Currículo, Cultura e Sociedade. 12 ed. São Paulo: Cortez, 2011.

PACHECO, J. A. Políticas Curriculares: referências para análise. Porto Alegre: Artmed, 2003.

PLETSCH, Marcia Denise. Repensando a inclusão escolar de pessoas com deficiência mental: diretrizes políticas, currículo e práticas pedagógicas. Tese (Doutorado em Educação) - Universidade do Estado do Rio de Janeiro. Rio de Janeiro: ProPed/UERJ, 2009.

PLETSCH, M. Denise; SOUZA, Flávia F.; OLEANS, Luis F. A diferenciação curricular e o desenho universal na aprendizagem como princípios para a inclusão escolar. Revista Educação e Cultura Contemporânea, v. 14, n. 35, p. 264-261. 2017. Disponível em: <http://periodicos.estacio.br/index.php/reeduc/ article/view/3114/1662>. Acesso em: 07 set. 2018.

REDIG, A. G. Reflexões sobre a inclusão de alunos com deficiência intelectual no ensino comum. In: PLETSCH, M. D.; DAMASCENO, A. (Orgs.). Educação Especial e Inclusão Escolar. Seropédica, RJ: Ed. Da UFRRJ, 2011. p.7382.

ROLDÃO, Maria C. Diferenciação curricular e inclusão. In: RODRIGUES, David. (Org.). Perspectivas sobre a inclusão: da educação à sociedade. Porto: Editora Porto, 2003.

ROPOLI, E. A. et al. A educação especial na perspectiva da inclusão escolar: a escola comum inclusiva. Brasília: Ministério da Educação, Secretaria de Educação Especial; Fortaleza: Universidade Federal do Ceará, 2010. 
SACRISTÁN, J. G. O currículo: os conteúdos do ensino ou uma análise prática? In: SACRISTÁN, J. G; GÓMES, A. I. P. Compreender e transformar o ensino. 4. ed. Porto Alegre: ArtMed, 1998.

SACRISTÁN, J. Gimeno. Currículo: uma reflexão sobre a prática. 3. ed. Porto Alegre: ARTMED, 2000.

SILVA, F.C.T. Estudo de documentos curriculares locais e suas Implicações para a Construção da diferenciação/flexibilização curricular (1998-2008). Revista e-curriculum, São Paulo, v. 8. n. 2, ago. 2012. Disponível em: <https://revistas.pucsp.br/index.php/curriculum/article/view/10851/8052>. Acesso em: 10 ago. 2018.

SILVA, F.C.T. Documentos curriculares e as flexibilizações: escrita histórico-social do currículo em educação especial. Observatórios de Educação Especial e Inclusão Escolar. Revista Teias, v. 17, n. 46, jul./set. 2016. Disponível em: <https://www.e-publicacoes.uerj.br/index.php/revistateias/article/view/25498/18550>. Acesso em: 18 set. 2018.

YOUNG, M. Para que servem as escolas?. Educação e Sociedade. Campinas, vol. 28, n. 101, p. 1287-1302, set./dez. 2007. Disponível em: <http://www.scielo.br/pdf/es/v28n101/a0228101.pdf>. Acesso em: 15 set 2018.

YOUNG, Michael, F. D. Teoria do currículo: o que é e por que é importante. Cadernos de Pesquisa. São Paulo, v. 44, n. 151, p. 190-202, mar. 2014. Disponível em: <http://www.scielo.br/pdf/cp/v44n151/10.pdf>. Acesso em: 08 set. 2018. 


\section{RESUMO}

A educação inclusiva assenta-se no reconhecimento e valorização da diferença. Enquanto prática, pode se estruturar por meio de mecanismos de diferenciação curricular que possibilitem a todos/as acesso à educação como bem comum. Contudo, tal perspectiva vem sendo confrontada pela atual política curricular para a educação básica. Diante disso, este texto objetiva problematizar a política curricular para os anos iniciais do ensino fundamental, com foco no primeiro e segundo anos de escolarização, sedimentadas na Base Nacional Comum Curricular e no Programa Mais Alfabetização, produzindo inferências sobre os efeitos que estas podem trazer às práticas curriculares no contexto da inclusão.

Palavras-chave: Diferenciação curricular. Políticas curriculares. Educação Inclusiva.

\section{THE CURRICULUM POLICY IN THE CONTEXT OF INCLUSION AND ITS MECHANISMS OF CURRICULAR DIFFERENTIATION}

\section{ABSTRACT}

Inclusive education, is based on the respect and appreciation of difference. As a practice, can be structured through mechanisms of curricular differentiation that enable all subjects to access education as a common good. However, this perspective has been strongly confronted through political curricular for Basic Education. Before this scenario, this text aims to problematize the curricular policy for the initial years of elementary school, focusing on the first and second year of schooling, established in the National Curricular Common Base (NCCB) and the More Literacy Program, inferences are made about the effects that this policy can bring to curricular practices in the context of inclusion.

Keywords: Curricular differentiation. Curricular policies. Inclusive education.

\section{LA POLÍTICA CURRICULAR EN EL CONTEXTO DE LA INCLUSIÓN Y SUS MECANISMOS DE DIFERENCIACIÓN CURRICULAR}

\section{RESUMEN}

La educación inclusiva, se asienta en la valorización de la diferencia. Aunque práctica, se puede estructurar por medio de mecanismos de diferenciación curricular que posibiliten a todos los sujetos el acceso a la educación como un bien común. Con todo, tal perspectiva viene siendo fuertemente confrontada por la actual política para la educación básica. Frente a este escenario, este texto busca problematizar la política curricular para los años iniciales de la escuela primaria, enfocándose en el primer y segundo año de escolarización, sustentada en la Base Nacional Común Curricular (BNCC) y en el Programa Más Alfabetización, son realizadas inferencias sobre los efectos que esa política puede traer para las prácticas curriculares en el contexto de la inclusión.

Palabras-clave: Diferenciación curricular. Políticas curriculares. Educación Inclusiva. 